•生物编目・

\title{
蔷薇科Docynia之中文名宜为“多依属”
}

\author{
刘华杰 $^{1^{*}}$ 马金双 ${ }^{2,3}$ 刘 夙 ${ }^{2}$ 刘 冰 $^{4}$ \\ 1 (北京大学哲学系, 北京 100871) \\ 2 (中国科学院上海辰山植物科学研究中心, 上海 201602) \\ 3 (上海辰山植物园, 上海 201602) \\ 4 (中国科学院植物研究所系统与进化植物学国家重点实验室, 北京 100093)
}

\section{On the Chinese name for genus Docynia (Rosaceae)}

\author{
Huajie $\mathrm{Liu}^{1 *}$, Jinshuang $\mathrm{Ma}^{2,3}$, Su Liu${ }^{2}$, Bing $\mathrm{Liu}^{4}$ \\ 1 Department of Philosophy, Peking University, Beijing 100871 \\ 2 Shanghai Chenshan Plant Science Research Center, Chinese Academy of Sciences, Shanghai 201602 \\ 3 Chenshan Botanical Garden, Shanghai 201602 \\ 4 State Key Laboratory of Systematic and Evolutionary Botany, Institute of Botany, Chinese Academy of Sciences, Beijing \\ 100093
}

科学志书属于社会文化基础工程, 影响巨大, 为便于文化传播, 其分类名称宜采用易输入的规范 汉字。分布在我国云南、四川、贵州有较好开发前 景的蓄薇科Docynia属乔木, 结实率较高, 果实类似 小苹果, 有不规则针棱(图1)。此属全球有5种, 中国 2种。其中文名用了生僻、难写的汉字“栘柿”。《中 国植物志》(中国科学院中国植物志编辑委员会, 1974)在脚注中标出此中文属名来源于1958年出版 的《中国种子植物科属辞典》, 其他异名有多胜属、 栘柛属。

这两个字如何发音呢？第一个字“栘”极不常用, 它只有一个音yí。第二个字 “柿”读作 $\mathrm{y} \overline{1}$, 一般的输入 法无法输入, 目前许多计算机字体(如Word的宋体) 也缺少相关字模。《中国植物志》和Flora of China (Wu et al, 2007, 以下简称FOC)中都使用了造字, 电子版甚至用“[木+衣]”代表“柿”字。《现代汉语词 典》第7版(中国社会科学院语言研究所, 2016)在解 释“栘”和“柿”两字时, 都唯一指向一种乔木名“栘 柿”, 读音是 yí y $\mathrm{y}$ 。也就是说这两个汉字是专门为这 类植物设定的。

但是FOC在标出中文字的读音时却这样写着: 栘柿属duo yi shu, 栘柿duo yi, 云南栘柿yun nan duo yi。然而汉语中“栘”字并没有duo的音, 显然编写植 物志的学者不知道“栘”如何发音。

《植物傣名及其释义》(许再富等, 2015)对“云 南多依 Docynia delavayi”的解释为: 麻过缅 (maguo-mian)。其中麻是“果树”的意思, 过缅是“生长在 高海拔”的意思。《云南德宏州高等植物》(刘世龙 和赵见明, 2009)对 “云南栘柿”的处理是: 桃柿柿、小 木瓜、酸栘柿、酸多李皮、楂子果; ma gua (D)。之 后列出了当地民族对此植物的几种发音: me guang xi (J); mu guo shi (Z)。其中D指傣族, J指景颇族, Z 所指不明(可能指汉族。奇怪的是, 此工具书并无体 例说明，查遍全书找不到对所用符号的说明)。

以上两者对比发现, 发音相似, 略有不同。而 不同地方的傣语本来就有差异。2018年8月本文作 者实地调查发现, 西双版纳预海县多个地方的傣族 人和哈尼族人都非常一致地把这类植物叫作 $\mathrm{duō} \mathrm{y} \overline{1}$, 其果实叫作 $d u \bar{o}$ yī 果。我们特意询问了当地林业部 门的工作者, 他们的发音也是 $\mathrm{duō} y \overline{\mathrm{y}}$ 。在云南, 普通 百姓大多认识这个属的植物, 早市上就有出售这类 野果的, 当地人也把它做成果脯, 称之为“多衣”或 “姚姨”(《中国植物志》记载了这个云南本地名)。 预海县内还有地名多依寨、多依村, 依有时写作衣, 

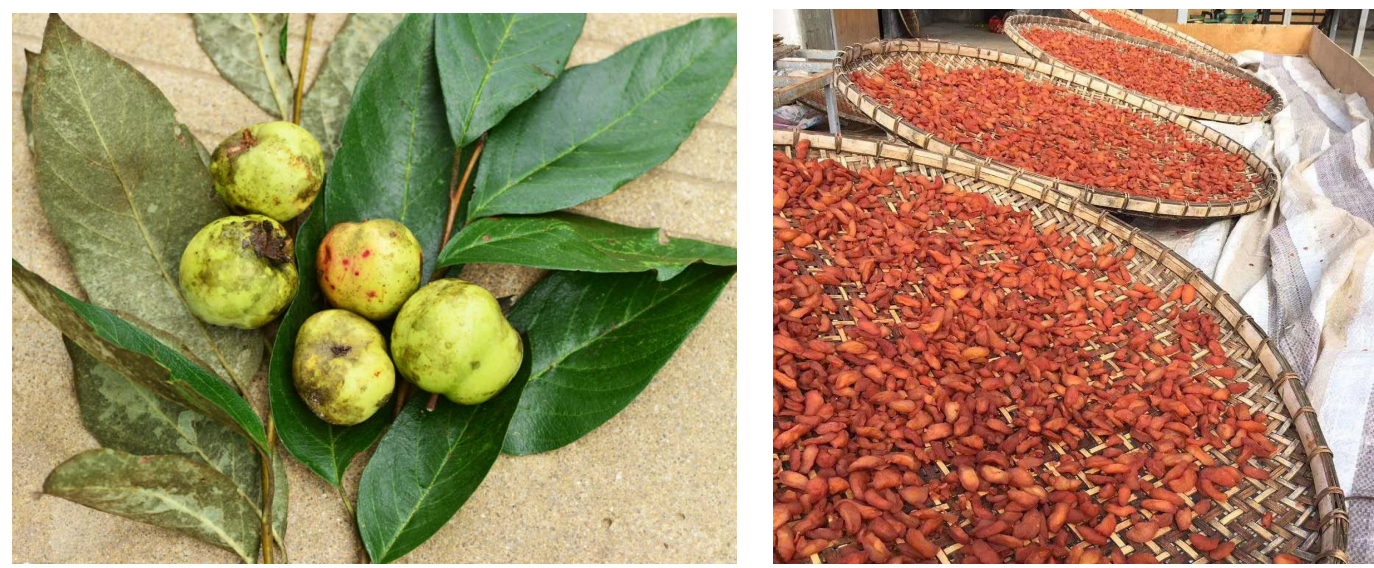

图1 蔷薇科植物多依(左图, 刘华杰摄于云南虸海)和云南虸海人家晒制的多依果干(右图, 佐连江摄影)

Fig. 1 Duoyi (Docynia indica) in Rosaceae (left, photographed by Liu Huajie at Menghai, Yunnan Province) and Duoyi dried fruits at Menghai, Yunnan Province (right, photographed by Lianjiang Zuo).

实地调查也确认这些地名与此植物直接相关。

这就出现了明显的矛盾。鉴于 “栘柿”这两个字 极少用、易读错、也很难输入, 为便于学习和交流, 可考虑修订Docynia的中文名。

综合来看, 有如下几种修改方案: (1)移衣, 读 yí ȳi ; (2)姚姨, 读yáo yí; (3)多衣, 读duō yī; (4)多依, 读 $\mathrm{du} \overline{\mathrm{y}} \mathrm{y} \overline{\mathrm{1}}$ 。

四种方案各有利弊。如果要保持原来的发音, 并使之与历史文献对应，可考虑改写作“移衣”，但 这与实际的发音不符。如果延续现在民间的常用读 法，可写作“多衣”或“多依”。如果从民族植物学的 角度考虑, 可写作 “姚姨”, 但是现在当地的民族也 不再如此发音。我们倾向于从俗从简, 照顾到现在 普遍的读音，索性“将错就错”，写作“多依”，即采 用第4种方案，与《植物傣名及其释义》用法一致。 与《中国植物志》和FOC相比, 相当于改正了读音, 同时换了两个容易输入的汉字。建议下一版《中国 植物志》能够采用“多依属”这一名称。

为何不彻底简化写作 “多衣”呢? 因为在云南 “依”字用得更多; 而“衣”字可能造成误解, 容易被 误以为是表意。于是我们认为Docynia宜称“多依属”, Docynia delavayi称“云南多依”, 另一个种Docynia indica称“多依”。这样做虽然可能斩断了最初命名时 与古代文化的渊源(其实, 目前没有可靠资料可以 证明“栘柿”与古代字书上读“移”的“栘”字有继承关
系)，但好处是与现在民间的普遍称谓相符，毕竟便 于使用是命名的一项重要考虑。另外 duōo的发音与 拉丁属名的起始部分读音相近，也便于记忆。这与 物理学名词turbulence中文称“湍流”(王竹溪先生的 贡献), 有同样的效果。

\section{参考文献}

Delecti Florae Reipublicae Popularis Sinicae Agendae Academiae Sinicae (1974) Flora Reipublicae Popularis Sinicae, Tomus 36, pp. 345-347. Science Press, Beijing. (in Chinese) [中国科学院中国植物志编辑委员会 (1974) 中国植物志, 第36卷, 345-347页. 科学出版社, 北京.]

Liu SL, Zhao JM (2009) Advanced Plants of Dehong in Yunnan Province, Vol. 1, p. 384. Science Press, Beijing. (in Chinese) [刘世龙, 赵见明 (2009) 云南德宏州高等植物 (上册), 384页. 科学出版社, 北京.]

Institute of Linguistics of Chinese Academy of Social Sciences (2016) Modern Chinese Dictionary, 7th edn. pp. 1543-1544. Commercial Press, Beijing. (in Chinese) [中国社会科学院 语言研究所 (2016) 现代汉语词典, 第7版, 1543-1544页. 商务印书馆, 北京.]

Wu ZY, Raven PH, Hong DY (2007) Flora of China, 12, pp. 412-417. Science Press, Beijing \& Missouri Botanical Garden Press, St. Louis.

Xu ZF, Yan HD, Duan QW, Zhou HF (2015) Dai Names and Their Interpretation of Plants, p. 98. Science Press, Beijing. (in Chinese) [许再富，岩罕单，段其武，周惠芳 (2015) 植物傣名及其释义, 98页. 科学出版社, 北京.]

(责任编辑: 周玉荣) 